\title{
DESARROLLO HUMANO Y EDUCACIÓN FÍSICA ${ }^{1}$
}

\author{
HUMAN DEVELOPMENT AND PHYSICAL EDUCATION
}

\author{
José Alfonso Martín Reyes ${ }^{2}$ \\ Sonia López Domínguez ${ }^{3}$
}

\section{Resumen}

Este ensayo tiene el ánimo de compartir una percepción personal alrededor de los conceptos de desarrollo humano y educación física. Es un aporte primario y crítico alrededor de un tema que no pasa de moda en el ámbito educativo y al cual se hacen multitud de aproximaciones. No está enmarcado en una teoría en especial y mucho menos pretende ser conclusivo. Por tal razón, se evitará en lo posible dar definiciones y se enunciará, haciendo uso del pensamiento negativo, lo que "no son" los temas propuestos. En lugar de respuestas quedarán preguntas. Todo ello partiendo de un par de postulados.

Palabras claves: desarrollo humano; educación física; orden; desorden

\section{Abstract}

The purpose of this essay is to share a perception about the concepts of Human Development and Physical Education. It is a primary and critical contribution about a contemporary topic in the education field. It is neither framed within a particular theory nor does it intend to be conclusive. Therefore, definitions will be avoided as much as possible and it will be described using the negative method, what the proposed topics "are not". Instead of answers, questions will remain. This will be based on a couple of premises.

Keywords: human development; physical education; order; disorder

Fecha de recepción: 23 de octubre de 2015

Fecha de aprobación: 8 de marzo de 2016

Para citar este artículo:

Martín, J.A. y López, S. (2016). Desarrollo humano y educación física. Lúdica Pedagógica, (23), 143-147.

1 Resultado del proyecto de investigación "La formación docente en los programas de Licenciatura en Educación Física y Licenciatura en Recreación y Turismo" (código FEF395-15), liderada por el docente de planta Juan Manuel Carreño.

2 Magíster en Filosofía de la Universidad del Rosario; especialista en Teorías, Métodos y Técnicas de la Investigación Social, Universidad Pedagógica Nacional; especialista en Entrenamiento Deportivo, Universidad del Deporte Beijing, R. P. China, licenciado en Educación Física y docente de planta de la Universidad Pedagógica Nacional. Correo electrónico: alfonsom@pedagogica.edu.co

3 Magíster en Educación y Desarrollo Social upn-cinde; especialista en Investigación sobre el Fenómeno de las Drogas, Universidad de Sao Paulo, especialista en Docencia Universitaria, Universidad El Bosque; licenciada en Educación Física, UPN Docente de planta de la Universidad Pedagógica Nacional. Correo electrónico: solopez@pedagogica.edu.co 
Terminando el siglo pasado, directivos de las ligas deportivas del Distrito, nos encontramos por invitación del Instituto Distrital de Recreación y Deportes en un curso de Alta Gerencia Deportiva en la Universidad de los Andes. El curso en cuestión se ajustaba a la metodología de taller y en una de las prácticas la tarea consistió en encontrar 20 usos distintos para el estuche de un casete de audio. Ante el aluvión de disparatadas propuestas por parte de los cursillistas las explosiones de risa fueron frecuentes, pero al final logró decantarse una buena cantidad de insospechadas posibilidades de aplicación para un objeto acerca del cual se había considerado una única función.

Ejercicios como el mencionado son susceptibles de hacerse en cualquier momento y rompen el molde acostumbrado en la academia de definir y explicar para qué sirven los objetos y conceptos con los que interactuamos en nuestro transcurrir por el mundo de la vida. Encontrar en las cosas usos diferentes al establecido o enunciar para que "no sirven" puede llevar eventualmente a conocer de forma más profunda y completa el objeto estudiado. El agradable taller enseñó que plantear y descubrir usos o aspectos no previstos de los objetos o ideas con que nos cruzamos día a día permite dar rienda suelta a la imaginación y aumenta las posibilidades de comprender por una vía diferente.

Feng Youlan ${ }^{4}$ (1989) sostiene que el pensamiento occidental es en esencia de carácter positivo lo que explica su tendencia a definir y explicar dejando a un lado la intuición, mientras que el pensamiento de carácter negativo propio de oriente prefiere la intuición y por ello habla sobre lo que no es el objeto, obteniendo así alguna idea sobre lo que es, por un camino que aporta otros datos.

A la luz de este antecedente y para efectos del presente ensayo sobre desarrollo humano y educación física, no se partirá de las usuales definiciones, sino de la enunciación de unos postulados; después, se dirá "qué no es desarrollo humano" e igualmente "qué no es educación física". La expectativa ante tal planteamiento es no atar todos los cabos, sino dejarlos sueltos y al final conocer un poco más de cada concepto sin haber hecho de entrada el tradicional intento de definirlos o decir para que sirven.

Todo ello puede ser entendido como una crítica a la inveterada costumbre de que en los procesos académicos

4 Filosofo chino (1895-1990) gracias al cual se introdujo el estudio de la filosofía china en la era moderna. la información y las definiciones teóricas ocupan lugar preponderante, con lo que se deja un lugar restringido a la imaginación y el descubrimiento. La intención es abrir campo a una idea un tanto divergente.

\section{LOS POSTULADOS}

El primer postulado es que si miramos nuestra existencia desde una posición rigurosamente evolutiva se evidencia una continua prevalencia del orden sobre el desorden, sin objetar que en ese camino son aniquiladas un sinfín de posibilidades, o mejor, que ellas se desvanecen justo cuando las más exitosas toman lugar. Visto así, hacer un rápido recorrido por nuestros orígenes como especie arroja interesantes elementos en ese sentido y permite establecer una serie de sucesos para favorecer el primer postulado, fácilmente relacionables además con el desarrollo humano.

Es necesario de entrada aceptar la teoría del big bang (gran explosión), término introducido intencionalmente en 1949 por el astrofísico británico Fred Hoyle para bautizar la teoría planteada por el científico emigrado de Rusia George Gamow, con la cual, por cierto, no estaba de acuerdo, pero que hoy por hoy es la explicación más aceptada en el mundo científico acerca del origen del universo (Ferris, 1990, p. 170), una versión un poco diferente de este evento puede encontrarse en Asimov (1993, p. 65).

Después del big bang, se inició a fantásticas velocidades la formación de partículas básicas que en miles de millones de años estructuraron soles, quásares, agujeros negros, galaxias, sistemas solares como el nuestro y, por supuesto, la vida y nuestra especie. Del caos inicial y partiendo de los fragmentos resultantes, se estructuró el átomo considerado inicialmente por los físicos como indivisible, pero que luego dejó conocer su compleja y estable conformación constituida entre otros por electrones, protones, neutrones, leptones, hadrones, quarks y, el último de ellos, el elusivo bosón de Higgs ${ }^{5}$. Una partícula tan inestable que su vida media es de un zeptosegundo, (la miltrillonésima parte de un segundo),

5 Mediante el bosón de Higgs se puede explicar el origen de la masa en las partículas elementales y por tanto de nuestra existencia y todo los que nos rodea, por tal motivo fue apodada, "la partícula de Dios". Dos de los tres investigadores que postularon su existencia en 1964 recibieron el Premio Nobel de física de 2013. La existencia de la partícula fue determinada en laboratorio en 2012. http://hipertextual.com/2015/09/ boson-de-higgs-atlas-cms-cern 
pero culpable de la existencia de la masa. Así, se ilustran someramente los primeros triunfos del orden sobre el caótico inicio.

Más adelante aparece la molécula, originalmente considerada última unidad indivisible de una sustancia constituida por átomos, que ya permitió conocer por parte de los químicos su organizada estructura, su papel en los tejidos vivos, predecir su comportamiento e incluso ser manipulada. De la molécula puede decirse que efectivamente en caso de ser desintegrada pierde su identidad, como ejemplo, al desintegrar una molécula de agua se obtiene oxígeno e hidrógeno, pero el agua desaparece. De moléculas se forman las unidades básicas de los tejidos vivos, las proteínas y los aminoácidos. Este siguiente escalón añade un triunfo adicional del orden sobre el desorden.

Otra victoria mayúscula del orden fue la estructuración de la célula, constituida por moléculas y componente básico de toda materia viva, que ha revelado a los biólogos sus complejidades y las funciones específicas de cada uno de sus componentes. Se entendió, gracias a juiciosas observaciones con el microscopio, que cada célula constituía una unidad independiente de vida y que inclusive algunos microorganismos estaban estructurados por una única célula. La biología molecular permitió adentrarse en el mundo de los genes, los ácidos nucleicos, el ADN y el origen de la vida.

En esta línea de orden sucesivo, se puede sostener que desde el caos de la explosión primigenia hasta la aparición del ser humano y sus procesos de civilización fueron conformándose estructuras cada vez más complejas: átomos, moléculas, células, tejidos, órganos y sistemas hasta llegar a la rica diversidad de los seres del reino vegetal y animal, y su hermosa sincronía. Finalmente, surge la especie humana, autodenominada reina de la naturaleza, única que exhibe complejos procesos mentales, crea tecnología y una variada gama de procesos educativos, entre ellos escribir ensayos. Supuesto lo anterior, cabe preguntar: en esta serie sucesiva de éxitos del orden, ¿cuál debería ser el siguiente paso en la cadena de triunfos reseñados?, ¿se ha llegado al último escalón?

El segundo postulado es que la especie humana hace presencia en el mundo con el cuerpo. Gracias a él se existe, se tiene y da sentido a la vida; gracias a él se puede leer el mundo, establecer relaciones con otros, con el medio y satisfacer y construir la realidad.

El cuerpo a lo largo de la historia ha sido tratado como objeto y como sujeto. Después de discusiones nunca terminadas en tal sentido, en la actualidad hay aceptación para concebirlo como una unidad indivisible. Es decir, se tiene cuerpo objeto y se es cuerpo sujeto de forma simultánea. La dualidad ha sido superada al menos en la teoría, lo que permite colocarse en una posición de carácter holística.

Es indudable que el cuerpo humano presenta exquisitos logros y organizaciones internas que evidencian de manera irrefutable un constante triunfo del orden sobre el desorden. Sin embargo, hay plena conciencia del inexorable deterioro producto de los años, del dolor, el sufrimiento y la inevitable muerte, así como de los pertinaces sentimientos de rencor, odio, envidia y deseos de poder que acompañan su actuar.

Pese a ello, la preeminencia humana alcanzada respecto a los demás seres vivos del planeta es evidente. Gracias al primitivo pero eficaz mecanismo de ensayo y error, además, de las capacidades de producir, acumular y transmitir información es que el ser humano ha logrado adaptarse exitosamente a los cambios y exigencias del medio de manera adecuada. Ahora bien, como consecuencia de la capacidad de observar y en virtud de la interiorización evolutiva que significan esas experiencias y los movimientos de traslación conscientes e intencionales que ellas generan, es que se ha desarrollado el cerebro y afinado el pensamiento y la imaginación, propias de su función, lo que permite exhibir una particular y notable capacidad para hacer predicciones. Todo ello junto a las emociones que, siguiendo a (Llinás, 2002), “[...] son la razón de nuestro deseo de sobrevivir y de nuestra inspiración" (p. 181), juntan lo irracional con lo racional haciendo de la especie humana única y poderosa. Como puede verse, procesos de miles de millones de años para el universo y de mucho menos para la especie están relacionados, tendiendo hacia el orden como una constante.

\section{EL ENCUENTRO}

Buena parte de los exitosos eventos reseñados han sido naturales y sin intervención intencional alguna de la especie humana. Conociendo que todo ha significado 
miles de millones de años de cambios continuos, es claro que lo humano solo ocupa pequeñísimas fracciones de tiempo en el calendario cósmico y que eventualmente estamos condenados como especie a la extinción. Pero mientras ello ocurre tendremos cientos o miles de años más para habitar el planeta y el universo ${ }^{6}$.

Ante tal perspectiva y tomando como elemento los avances tecnológicos y de civilización logrados por el hombre, buena parte de los cambios necesarios para asegurar la supervivencia ahora sí están en nuestras manos y por ello se puede especular acerca de lo que no sería de esperar como siguiente escalón evolutivo en el desarrollo humano. Si se pregunta acerca de deseos o expectativas relativas al futuro de la especie, con certeza nuestra extinción recibiría pocos votos a favor y regresar al caos primario tampoco parece una salida probable en el corto plazo.

Por tanto, puede pensarse que el desarrollo humano no le apunta a la autoaniquilación de la especie. Que ante los cambios propios de una "modernidad líquida" (Bauman, 2008), es muy posible que la salida no sea el aislamiento y la hiperespecialización. Que pese a nuestra inexorable, hasta ahora, condición de mortales, el desarrollo humano tampoco le puede apuntar a la muerte temprana ni a la propagación de la enfermedad y el sufrimiento. Que el hambre y recursos inaccesibles para sectores amplios de la población igualmente no pueden ser epítome de desarrollo. El desarrollo humano no puede significar la carencia de posibilidades para desplegar las capacidades y llevar adelante las vidas individuales y de grupo. Igualmente, estar compelido a la obediencia ciega de instrucciones emanadas de un sistema de control no parece muy atractivo. Si no hay tiempo para la contemplación, para el ocio, para el turismo, ¿será factible hablar de desarrollo humano?

Tomemos ahora la educación física. Estar educado físicamente para saber cuidar de sí como cuerpo que se tiene y que se es, no es saber de memoria los músculos, los huesos, los sistemas, o pasar los test de evaluación de desarrollo de la capacidad física. Tampoco es estar en capacidad de derrotar a los demás en contiendas deportivas. Con certeza no está educado físicamente quien se

6 La certeza de nuestra extinción como consecuencia del colapso del sistema solar en unos 4500 millones de años fue lo que motivo al filósofo francés Jean François Lyotard a escribir su texto, "Lo inhumano". desconoce como cuerpo, quien no sabe de cuidado de sí o quien no establece las relaciones adecuadas con los demás y con el medio. No está educado físicamente quien deliberadamente se deteriora a sí mismo, quien habla de la importancia de los hábitos saludables de vida y no los ha incorporado a la suya. No está educado y no es formador quien se queda en el discurso. No está educado físicamente aquel que requiere recibir instrucciones para actuar, aquel que no se ha acercado al autodidactismo.

Cabe en estos momentos compartir algunas cavilaciones. Es indudable que la educación es uno de los factores encargados de garantizar el desarrollo. Pero cuando se queda en la mera transmisión de información solo conduce a un favorecimiento de la memoria, importante para presumir, resolver crucigramas y ser admirado. La extensión del estar informado conduce a una clase de erudito que es una especie de biblioteca ambulante depositaria de una enorme cantidad de datos, de esos hay muchos. La mera transmisión de datos solo garantiza que el mensaje fue entregado y que eventualmente el receptor está en capacidad de repetirlo fielmente, por lo general en un examen diseñado para tal fin. A veces la denominada didáctica se reduce a eliminar los ruidos y acelerar el proceso de memorización. Como se lee en Ferrater (2004): "No se trata de transmisión de conocimientos, sino simplemente de datos" (p. 1839). 0 como lo enuncia a menudo la maestra Judith Jaramillo: "No es lo mismo estar informado que estar formado"7.

No pasa igual cuando la información se transmite con sentido y significado, con énfasis en principios y utilidad, con vistas a la obtención de entendimiento. Siguiendo a Midgley (2002):

[...] es algo profunda y francamente deseado. Se puede considerar el conocimiento como un medio en sí mismo simplemente porque las personas encuentran la confusión angustiosa y destructiva. Necesitan entendimiento no solo para ganarse la vida, sino también para lograr que sus vidas valgan la pena. (p. 81).

Cuando se reflexiona profundamente acerca de la información recibida, se accede al conocimiento y no es lo mismo estar informado que tener conocimiento. La extensión del conocimiento conduce a la intelectualidad.

7 Judith Jaramillo de Palacios, docente de planta de la Facultad de Educación Física de la Universidad Pedagógica Nacional. 
En el mundo hay algunos intelectuales, otros que lo desean y otros más que presumen serlo.

Cuestión distinta ocurre cuando la información recibida y la reflexión aplicada sobre ella conducen a la incorporación de lo aprendido a la vida. Es decir, cuando hay total coherencia entre lo que se piensa, lo que se dice y lo que se hace. Ser como uno se expresa es un ideal. La extensión del saber es el sabio, la sabiduría. De esos sí que hay pocos.

Ante estas cavilaciones cabe preguntarse: ¿cuál debería ser el objetivo de la educación y su clara relación con el desarrollo?, ¿informar, conocer o saber?

Otros aspectos importantes alrededor del desarrollo humano y particularmente en lo que atañe a la educación física es que en ocasiones el rendimiento y la condición física objetiva se privilegian a costa de la formación que pasa a ser un adorno en las justificaciones. Se habla de valores y conductas, pero pocas veces se establece con certeza su manifestación. Por eso, tal vez se ha estudiado de manera exhaustiva el cuerpo que se mueve, pero no lo que lo mueve, el cerebro.

La atención, la observación, la memoria, el pensamiento, la imaginación y la creatividad también se pueden "entrenar". La inter, la multi, la transdisciplinariedad son a todas luces una necesidad. El desarrollo humano no es tarea exclusiva de un grupo de expertos en particular, sino de miradas amplias que permitan articular a las más diversas perspectivas, siempre y cuando no carezcan de rigurosidad. Desde la física, la química, la sociología, la filosofía, y otras disciplinas con todas las posibles combinaciones entre ellas, deben surgir las nuevas propuestas. Para darles trámite, además de juicio, se requerirá de coraje pues algunas podrán parecer de ciencia ficción. La pregonada inteligencia de la especie humana está a prueba, de ella depende el futuro de la humanidad, es decir, el desarrollo humano.

\section{CONCLUSIÓN}

A manera de conclusión puede aventurarse que, dados los ejemplos, es factible pensar que desde nuestros inicios el orden ha triunfado de manera sistemática sobre el desorden por millones de años y puede aún continuar haciéndolo. Por supuesto, y pensando en modo oriental, así como luz y su ausencia conforman los principios fundamentales del yang y el yin respectivamente, al igual que masculino-femenino, actividad-pasividad, calor-frío, dureza-blandura, y de la interacción de estos opuestos es que se generan los fenómenos del universo, es necesario un buen desorden para que florezca el orden, tal equilibrio o totalidad es lo que ellos denominan el tao.

Por otra parte, el cuerpo humano, eso que somos y tenemos, indudablemente es también producto de ese proceso. Los logros de orden y sincronía para mostrar en él son formidables y pese a todos los adelantos predecir con precisión a dónde vamos a llegar continúa siendo toda una aventura del pensamiento. Es bastante probable que aún no hayamos llegado al último peldaño de desarrollo como especie. Hay plena conciencia de nuestro carácter modificable, adaptable y perfectible y que ahora el desarrollo no corresponde tanto al azar, sino que está en nuestras manos y para eso tenemos a las ciencias y las humanidades, con sus cambiantes paradigmas. Con todo ello, una pregunta un tanto obvia podría ser: ¿qué sigue?

\section{REFERENCIAS}

Asimov, I. (1993). Nueva guía de la ciencia. Barcelona: Plaza \& Janés

Bauman, Z. (2008). Modernidad líquida. Buenos Aires: Fondo de cultura económica.

Ferrater, J. (2004). Diccionario de filosofía. Barcelona: Editorial Ariel.

Feng, Y. (1989). Breve historia de la filosofía china. Beijing: Ediciones en lenguas extranjeras.

Ferris, T. (1990). La aventura del universo. Barcelona: Grijalbo Mondadori.

Kuhn, T. S. (1994). La estructura de las revoluciones científicas. Bogotá: Fondo de Cultura Económica.

Lyotard, J. F. (1998). Lo inhumano. Charlas sobre el tiempo. Buenos Aires: Ediciones Manantial.

Llinás, R. (2002). El cerebro y el mito del yo. Bogotá: Norma editorial.

Midgley, M. (2002). Delfines, sexo y utopías. México, D. F.: Fondo de Cultura Económica. 
